\title{
Incidence of Influenza Among Childhood Cancer Survivors in South Korea: A Population-based Retrospective Analysis
}

\author{
JAESUNG HEO $^{1 *}$, HYUN JOO JUNG ${ }^{2 *}, \mathrm{O} \mathrm{KYU} \mathrm{NOH}^{1,3}$, LOGYOUNG KIM $^{4}$ and JUN EUN PARK ${ }^{2}$ \\ ${ }^{1}$ Department of Radiation Oncology, Ajou University School of Medicine, Suwon, Republic of Korea; \\ ${ }^{2}$ Department of Pediatrics, Ajou University School of Medicine, Suwon, Republic of Korea; \\ ${ }^{3}$ Office of Biostatistics, Ajou University School of Medicine, Suwon, Republic of Korea; \\ ${ }^{4}$ Health Insurance Review and Assessment Service, Seoul, Republic of Korea
}

\begin{abstract}
Background/Aim: We quantified the incidence, and identified risk factors for influenza infection among childhood cancer survivors in South Korea, an at-risk population. Patients and Methods: Nationwide health insurance claims data were used to assess the frequency of influenza among childhood cancer survivors (aged $<20$ years) diagnosed between January 2009 and April 2016. A multivariable logistic regression was constructed to identify risk factors for influenza. Results: Of 6,457 children cancer survivors, 1,704 (27.0\%) were diagnosed with influenza. Influenza was common in children $<5$ years old and infections were highest between late October and April. Over $60 \%$ of influenza treatment claims came from private clinics. Risk factors for influenza included age $<9$ years. Conclusion: Childhood cancer survivors are particularly atrisk for influenza infection during the traditional influenza season. Identifying risks for influenza infection will help to establish countermeasures for reducing the influenza infections in at-risk cancer surviving children.
\end{abstract}

With ongoing advances in science and medicine, the survival rates for childhood cancer has continued to improve. For example, in Korea, the five-year survival rate of childhood cancer has improved from $56.1 \%$ in $1993-1995$ to $80.3 \%$ in 2007-2011 (1). Given this remarkable increase in the number of long-term childhood cancer survivors, there is increasing

This article is freely accessible online.

*These Authors contributed equally to this study.

Correspondence to: Jun Eun Park, MD, Department of Pediatrics, Ajou University School of Medicine, 164 Worldcup-ro, Yeongtonggu, Suwon 16499, Republic of Korea. Tel: +82 312195168, e-mail: pedpje@ajou.ac.kr

Key Words: Influenza, childhood cancer survivors, South Korea. interest in identifying and remediating various complications suffered by long-term survivors (2). Of note, childhood cancer survivors experience an increased risk for morbidity and mortality resulting from infections and infection-related complications $(1,3,4)$. According to a study of the Childhood Cancer Survivor Study cohort, childhood cancer survivors are at an increased risk of infection-related mortalities compared to the US population as a whole. As well, survivors have a higher incidence of all-cause infection as well as higher rates of infection-related complications compared to their siblings $(2,5)$.

Paediatric cancer patients may experience delayed infection-related complications because of their underlying disease, or, as a result of receiving cancer fighting chemotherapy, which may cause immune dysfunction. Previous studies have shown that major immunity in most patients will generally recover up to 6-12 months after chemotherapy. However, profound deficiencies in lymphocyte function may make the patient vulnerable to infection (2, 6-8).

Influenza is a form of acute respiratory infections, which, across all age groups, affects $10-20 \%$ of the population each year. Most healthy people who are infected with influenza will improve on their own without any progressive sequelae. However, high-risk groups, including infants, older adults, and those with chronic diseases, are at an elevated risk for exacerbating their existing disease, or for developing additional complications. All patients with hematologic or solid cancers treated with chemotherapy are considered to be high risk for manifesting influenza-related complications (9); however, children with malignant disease are particularly vulnerable to influenza infection.

Medical data in Taiwan indicate that 82.4 patients per 100,000 children with cancer were hospitalised with an influenza infection between 1995 and 2005 (10). However, there are few reports which assess influenza infection through a longitudinal review of childhood cancer survivors (9). In this study, 10 years of childhood Health Insurance 
Review and Assessment Service (HIRA) data in South Korea were examined to evaluate longitudinally the incidence of influenza infection, and to identify risk factors of infection, in children under the age of 20.

\section{Patients and Methods}

The South Korean National Health Insurance (NHI) system collects medical data on every resident in South Korea. As such, Health Insurance Review and Assessment Service Claims data are generated for patients visits to medical institutions and are stored in the HIRA database. This database consists of four subgroup tables. The first is a general specification table that includes patient demographics (patient sex, age, and residential area), institutional characteristics (location, department, and admission), and diagnostic data. The second table details patient medical histories and contains information on the provided procedures and prescribed medications provided during hospitalisation. The third table contains diagnostic data and allowed us to search for additional patient diagnoses in addition to their main diagnosis. The fourth table includes information about drug prescribed outside of the hospital.

Patients aged under 20 years who were diagnosed with paediatric tumours between January 2007 and December 2016 were identified by the HIRA claims database. For our analysis, we included patients who were diagnosed with one of the top 10 most common paediatric cancer subgroups, a subset which accounted for the majority of all paediatric cancers. The 10 identified subgroups of childhood cancer included leukaemia (C91-C95), brain tumour (C71), lymphoma (C83, C81-C82, C84-85), neuroblastoma (C74), ovary and testis malignancy (C56-C58, C62), soft tissue sarcoma (C49), bone and cartilage tumour (C40), Wilms tumour (C64), retinoblastoma (C69), and hepatic tumour (C22). To find first cancer diagnoses in 2009, those who were diagnosed with any form of cancer between 2007 and 2008 were excluded. The patients did not require oncology treatment for any type of cancer during the 2-year period (2-year washout period). This study was approved by the institutional review board (IRB) of the Ajou University Hospital (IRB No. AJIRB-MED-EXP-18-441).

To identify influenza infections among childhood cancer survivors, we searched the medical claim dataset (including all hospital admissions, medical office visits, and emergency room visits) for all diagnostic codes corresponding to an influenza infection, using ICD-10 as the principal diagnosis. The diagnostic codes included J9 (Influenza due to specific identified influenza virus), J10 (Influenza due to other identified influenza virus), and J11 (Influenza, virus not identified). We confirmed the only diagnosis of influenza that occurred after cancer diagnosis.

We investigated the time-course incidence of influenza in patients who were previously diagnosed with childhood cancer. Descriptive statistics were employed to estimate the frequency of influenza infection based on the date of diagnosis. Additionally, we evaluated various characteristics of childhood cancer survivors with influenza disaggregated by age. To analyse medical institution utilisation patterns, we classified hospitals as primary, secondary, and tertiary medical institutions using institution-type identifiers, which are based on their size. Primary medical institutions included clinics and public health centres, secondary medical institutions included hospitals and general hospitals, and tertiary medical institutions referred to advanced general hospitals. Between-group differences were evaluated using the Student's $t$ - and $\chi^{2}$-tests for continuous and
Table I. Frequency of influenza in childhood cancer survivors.

\begin{tabular}{lcr}
\hline Age & Childhood cancer survivors & Influenza (\%) \\
\hline$<1$ & 500 & $184(36.8)$ \\
$1 \sim 5$ & 1,648 & $631(38.2)$ \\
$6 \sim 10$ & 1,173 & $368(31.3)$ \\
$11 \sim 15$ & 1,588 & $321(20.2)$ \\
$>15$ & 1,548 & $200(26.4)$ \\
Total & 6,457 & $1,704(27.0)$ \\
\hline
\end{tabular}

categorical variables, respectively. Multivariate logistic regression analyses were used to estimate adjusted odds ratios (OR) between treatment subgroups and to explore whether demographic factors influence the development of influenza. Two-sided $p$-values of less than 0.05 were considered statistically significant. All statistical analyses were performed using the R 3.0.2 (R Foundation for Statistical Computing, Vienna, Austria) software package.

\section{Results}

A total of 6,457 childhood cancer survivors, including 3,661 boys and 2,796 girls, who were diagnosed with cancer between 2009 and 2016 were identified based on HIRA claim data. The most common cancer in all childhood cancer survivors was leukaemia $(\mathrm{n}=2441,37.8 \%)$, followed by brain tumours $(\mathrm{n}=1057,16.4 \%)$, lymphomas $(\mathrm{n}=739,11.4 \%)$, bone and soft tissue cancers $(\mathrm{n}=699,10.8 \%)$, and neuroblastoma $(\mathrm{n}=277,4.3 \%)$. Of the children included in this survey, 1,704 were diagnosed with an influenza infection. The overall incidence of influenza infection in childhood cancer survivors was $27.0 \%$. Considering how the incidence of influenza differed by age group, young children (under 5 years old) were most commonly affected, and the incidence declined after the age of 10 (Table I).

The incidence of influenza infection in childhood cancer survivors showed seasonal changes (Figure 1A). The frequency of influenza sharply increased beginning in late October, and did not substantially decline until April. This trend is similar to the influenza season among the general population (Figure 1B). Somewhat surprisingly, childhood cancer survivors were most frequently diagnosed with the influenza when treated at private clinics (62\%) (Figure 2).

Table II shows that there was a significant difference in the incidence of influenza based on the cancer treatment regimen $(p<0.001)$. Children who received chemotherapy had the highest incidence of influenza infection, while children who received only radiotherapy demonstrated the least incidence rates of influenza, which were even lower than those who did not receive either chemotherapy or radiotherapy. Multivariate analysis showed that being under 9 years of age $(\mathrm{OR}=0.37$, $p<0.001)$ was a risk factor for influenza infection among childhood cancer survivors (Table III). On the other hand, the incidence of influenza in patients receiving radiotherapy 
A

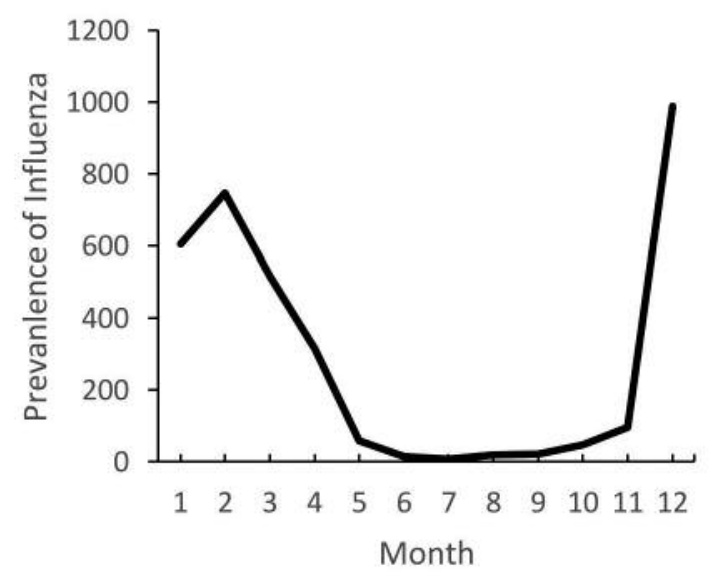

B

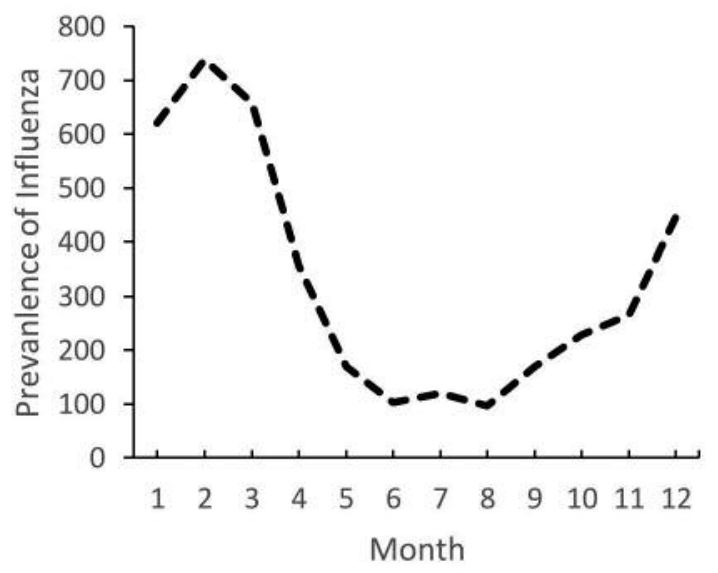

Figure 1. Monthly incidence of influenza among (A) cancer survivors and (B) the general population (2009-2016).

alone did not differ from that of patients who did not receive either chemotherapy or radiotherapy $(\mathrm{OR}=0.77, p=0.239)$. Among infected patients, the average influenza onset time after cancer treatment was 6-12 months for patients who received only chemotherapy, 18-24 months for patients who received both chemotherapy and radiotherapy, and 24-30 months for patients who received only radiotherapy.

\section{Discussion}

Pandemic influenza that occur annually among children around the world are one of the major health problems. (11, 12). Like in all children, influenza infection among children with malignancies leads to increased numbers of missed school days for children, missed working days for caregivers who must care for their children, and excess healthcare costs $(13,14)$. Previous research has documented the presence of seasonal influenza outbreaks among patients with malignancies and suggests that cancer patients are at high risk for acquiring influenza infections in health care settings $(10,15-17)$. In this study, we evaluated the incidence of influenza infection among childhood cancer survivors.

Among the patient population included in this study, the most common cancer was leukaemia $(37.8 \%)$, which was followed by brain tumours and lymphomas. This pattern was similar to the distribution of cancers previously reported among all patients in Korea (1). Influenza infection among childhood cancer survivors was most common in children under 5 years of age, but this incidence decreased with age (Table I). Based on the data presented in the Infectious Disease Surveillance Report by The Korea Center for Disease Control and Prevention (2014-2018), our observed pattern of influenza infection among childhood cancer survivors, is similar to the age distribution

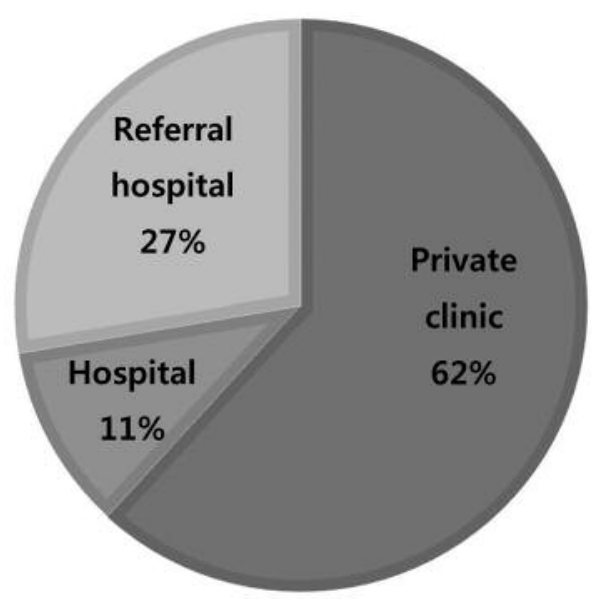

Figure 2. Proportion of childhood cancer survivors with an influenza infection diagnosed at each type of medical institution.

seen among normal children in Korea (18). Monthly incidence of influenza infection in childhood cancer survivors was similar to that in normal children (Figure 1). Likewise, Figure 1 shows that the incidence of influenza among cancer patients may be similar to that of normal patients.

In this study, we found that a high proportion of cancer patients with influenza were diagnosed in private clinics (Figure 2). Primary physicians may lack the knowledge and experience to manage cancer survivors. Therefore, primary care physicians should be trained on how to prevent and treat influenza in immunosuppressive patients, including cancer survivors. We also analysed how the incidence of influenza infection among childhood cancer survivors differed by treatment modality. Table II showed that the frequency of influenza was 
Table II. Frequency of influenza disaggregated by the patient's treatment modality $(N=6,457)$.

\begin{tabular}{lccc}
\hline & \multicolumn{3}{c}{ No. of patients (\%) } \\
\cline { 2 - 4 } Treatment & $\begin{array}{c}\text { Influenza (-) } \\
(\mathrm{n}=4,753)\end{array}$ & $\begin{array}{c}\text { Influenza (+) } \\
(\mathrm{N}=1,704)\end{array}$ & $p$-Value \\
\hline None & $793(76.7)$ & $241(23.3)$ & $<0.001$ \\
RT only & $137(82.0)$ & $30(18.0)$ & \\
CT only & $2,520(70.1)$ & $1,075(29.9)$ & \\
RT+CT & $1,303(78.4)$ & $358(21.6)$ & \\
\hline
\end{tabular}

RT: Radiotherapy; CT: chemotherapy.

significantly higher in patients who receive chemotherapy than in patients who receive radiotherapy. On average, the onset of influenza after cancer treatment was earliest in those treated with chemotherapy alone (6-12 months) and the latest in those treated with radiotherapy alone (24-30 months). Collectively, this indicates that influenza occurs earlier and more often in patients receiving chemotherapy, and later and less frequently in those receiving radiotherapy.

A multivariable analysis of risk factors indicated that an age under 9 years old was associated with influenza infection in childhood cancer survivors (Table III). Also, receiving chemotherapy has shown a tendency to influenza infection. Previous work showed that lymphopenia induced by chemotherapy was commonly detected in cancer patients who were hospitalised for influenza (16). Therefore, it is not surprising that the risk of influenza is high in patients treated with chemotherapy.

It is interesting to note that the incidence of influenza infection was not higher in children who received radiation therapy than in children who did not receive either chemotherapy or radiotherapy. It is difficult to clarify the reason for this phenomenon from our analysis. However, we speculate that strong droplet precaution practices among radiotherapy patients may underly their reduced risk for influenza. Droplet precautions, which are based on hand hygiene, social distancing, and personal protective equipment, such as facemasks, are basic and effective strategies for preventing the transmission of influenza (19, 20). Moreover, vaccinations and droplet precautions represent principle strategies for preventing influenza infection $(21,22)$. When patients are receiving cancer therapies, such as radiotherapy, patients or guardians are particularly careful about maintaining personal precautions and this can be effective in preventing influenza infection. However, despite practicing droplet precautions, children undergoing chemotherapy remain vulnerable to influenza infection. This is because chemotherapy induces immunosuppression, such as lymphopenia, much more
Table III. Multivariable analysis of risk factors for influenza in childhood cancer survivors $(N=6,457)$.

\begin{tabular}{lcc}
\hline Variable & $\begin{array}{c}\text { Odds ratio } \\
(95 \% \text { confidence interval) }\end{array}$ & $p$-Value \\
\hline $\begin{array}{l}\text { Gender } \\
\text { Male }\end{array}$ & 1 & \\
Female & $0.99(0.89-1.12)$ & 0.920 \\
Age & 1 & \\
$\leq 9$ & $0.37(0.33-0.42)$ & \\
$>9$ & & \\
Treatment & 1 & 0.001 \\
None & $0.77(0.50-1.19)$ & 0.239 \\
RT only & $1.15(0.97-1.36)$ & 0.028 \\
CT only & $0.81(0.67-0.98)$ & \\
RT+CT & & \\
\hline
\end{tabular}

RT: Radiotherapy; CT: chemotherapy.

strongly than radiotherapy. Collectively, our findings suggest that influenza prevention strategies are important for children with cancer, a population of immunocompromised patients.

In conclusion, influenza infection can cause serious complications, especially in high-risk patients, and thus, managing influenza is an important factor for improving the quality of life of childhood cancer survivors. In this study, we found that the monthly incidence of influenza among childhood cancer survivors was similar to that of the general population. Moreover, we found that children under 9 years of age were at high risk for influenza infection. Interestingly, our study also found that patients who received radiation alone had a similar incidence of influenza as those who did not receive either chemotherapy or radiotherapy. Collectively our findings show that it is necessary to assess the differential risks for influenza infection among childhood cancer survivors and to implement appropriate preventive measures to reduce influenza infection in high-risk subsets of childhood cancer survivors.

\section{Conflicts of Interest}

There are no conflicts of interest to disclose regarding this study.

\section{Authors' Contributions}

All Authors took part in the design of the study, contributed to data collection, and participated in writing the manuscript.

\section{Acknowledgements}

The Authors would like to thank Editage (www.editage.co.kr) for English language editing. This research was supported by the Bio \& Medical Technology Development Program of the National Research Foundation (NRF) funded by the Korean government (MSIT) (No. 2020M3A9E8024907). 


\section{References}

1 Park HJ, Moon EK, Yoon JY, Oh CM, Jung KW, Park BK, Shin $\mathrm{HY}$ and Won YJ: Incidence and survival of childhood cancer in korea. Cancer Res Treat 48(3): 869-882, 2016. PMID: 26790965. DOI: $10.4143 /$ crt.2015.290

2 Perkins JL, Chen Y, Harris A, Diller L, Stovall M, Armstrong GT, Yasui Y, Robison LL, Sklar CA and Childhood Cancer Survivor S: Infections among long-term survivors of childhood and adolescent cancer: A report from the childhood cancer survivor study. Cancer 120(16): 2514-2521, 2014. PMID: 24824782. DOI: $10.1002 / \mathrm{cncr} .28763$

3 Arpaci T and Kilicarslan Toruner E: Assessment of problems and symptoms in survivors of childhood acute lymphoblastic leukaemia. Eur J Cancer Care (Engl) 25(6): 1034-1043, 2016. PMID: 27647691. DOI: 10.1111/ecc.12561

4 Lorenzi MF, Xie L, Rogers PC, Pritchard S, Goddard K and McBride ML: Hospital-related morbidity among childhood cancer survivors in british columbia, canada: Report of the childhood, adolescent, young adult cancer survivors (cayacs) program. Int J Cancer 128(7): 1624-1631, 2011. PMID: 21280033. DOI: $10.1002 / \mathrm{ijc} .25751$

5 Mueller BA, Doody DR, Weiss NS and Chow EJ: Hospitalization and mortality among pediatric cancer survivors: A populationbased study. Cancer Causes Control 29(11): 1047-1057, 2018. PMID: 30187228. DOI: 10.1007/s10552-018-1078-0

6 Crawford NW, Heath JA, Ashley D, Downie P and Buttery JP: Survivors of childhood cancer: An australian audit of vaccination status after treatment. Pediatr Blood Cancer 54(1): 128-133, 2010. PMID: 19785022 . DOI: $10.1002 /$ pbc. 22256

7 Kang DH, Weaver MT, Park NJ, Smith B, McArdle T and Carpenter J: Significant impairment in immune recovery after cancer treatment. Nurs Res 58(2): 105-114, 2009. PMID: 19289931. DOI: 10.1097/NNR.0b013e31818fcecd

8 van Tilburg CM, van Gent R, Bierings MB, Otto SA, Sanders EA, Nibbelke EE, Gaiser JF, Janssens-Korpela PL, Wolfs TF, Bloem AC, Borghans JA and Tesselaar K: Immune reconstitution in children following chemotherapy for haematological malignancies: A long-term follow-up. Br J Haematol 152(2): 201-210, 2011. PMID: 21114483. DOI: 10.1111/j.13652141.2010.08478.x

9 Kersun LS, Reilly AF, Coffin SE and Sullivan KE: Protecting pediatric oncology patients from influenza. Oncologist 18(2): 204-211, 2013. PMID: 23370325. DOI: 10.1634/theoncologist. 2012-0401

10 Tai Y, Lee TC, Chang HL and Chen KT: Epidemiology and outcomes of hospitalization of influenza in the cancer population in taiwan. J Cancer Res Clin Oncol 135(8): 1061-1066, 2009. PMID: 19152001. DOI: 10.1007/s00432-009-0545-0

11 Lafond KE, Nair H, Rasooly MH, Valente F, Booy R, Rahman M, Kitsutani P, Yu H, Guzman G, Coulibaly D, Armero J, Jima D, Howie SR, Ampofo W, Mena R, Chadha M, Sampurno OD, Emukule GO, Nurmatov Z, Corwin A, Heraud JM, Noyola DE, Cojocaru R, Nymadawa P, Barakat A, Adedeji A, von Horoch M, Olveda R, Nyatanyi T, Venter M, Mmbaga V, Chittaganpitch M, Nguyen TH, Theo A, Whaley M, Azziz-Baumgartner E, Bresee J, Campbell H, Widdowson MA and Global Respiratory Hospitalizations-Influenza Proportion Positive Working G: Global role and burden of influenza in pediatric respiratory hospitalizations, 1982-2012: A systematic analysis. PLoS Med
13(3): e1001977, 2016. PMID: 27011229. DOI: 10.1371/journal. pmed.1001977

12 Nair H, Brooks WA, Katz M, Roca A, Berkley JA, Madhi SA, Simmerman JM, Gordon A, Sato M, Howie S, Krishnan A, Ope M, Lindblade KA, Carosone-Link P, Lucero M, Ochieng W, Kamimoto L, Dueger E, Bhat N, Vong S, Theodoratou E, Chittaganpitch M, Chimah O, Balmaseda A, Buchy P, Harris E, Evans V, Katayose M, Gaur B, O'Callaghan-Gordo C, Goswami D, Arvelo W, Venter M, Briese T, Tokarz R, Widdowson MA, Mounts AW, Breiman RF, Feikin DR, Klugman KP, Olsen SJ, Gessner BD, Wright PF, Rudan I, Broor S, Simoes EA and Campbell H: Global burden of respiratory infections due to seasonal influenza in young children: A systematic review and meta-analysis. Lancet 378(9807): 1917-1930, 2011. PMID: 22078723. DOI: 10.1016/S0140-6736(11)61051-9

13 Iskander M, Booy R and Lambert S: The burden of influenza in children. Curr Opin Infect Dis 20(3): 259-263, 2007. PMID: 17471035. DOI: $10.1097 /$ QCO.0b013e3280ad4687

14 Kempe A, Hall CB, MacDonald NE, Foye HR, Woodin KA, Cohen HJ, Lewis ED, Gullace M, Gala CL, Dulberg CS and Katsanis E: Influenza in children with cancer. J Pediatr 115(1): 3339, 1989. PMID: 2738793. DOI: 10.1016/s0022-3476(89)80325-7

15 Whimbey E, Elting LS, Couch RB, Lo W, Williams L, Champlin RE and Bodey GP: Influenza a virus infections among hospitalized adult bone marrow transplant recipients. Bone Marrow Transplant 13(4): 437-440, 1994. PMID: 8019468.

16 Tasian SK, Park JR, Martin ET and Englund JA: Influenzaassociated morbidity in children with cancer. Pediatr Blood Cancer 50(5): 983-987, 2008. PMID: 18240170. DOI: 10.1002/ pbc. 21472

17 Marcotte EL, Ritz B, Cockburn M, Yu F and Heck JE: Exposure to infections and risk of leukemia in young children. Cancer Epidemiol Biomarkers Prev 23(7): 1195-1203, 2014. PMID: 24793957. DOI: 10.1158/1055-9965.EPI-13-1330

18 Korea Influenza Sequence \& Epitope Database. Available at http://influenza.cdc.go.kr

19 Uchida M, Kaneko M, Hidaka Y, Yamamoto H, Honda T, Takeuchi S, Saito M and Kawa S: Effectiveness of vaccination and wearing masks on seasonal influenza in matsumoto city, japan, in the 2014/2015 season: An observational study among all elementary schoolchildren. Prev Med Rep 5: 86-91, 2017. PMID: 27981021. DOI: 10.1016/j.pmedr.2016.12.002

20 Cowling BJ, Chan KH, Fang VJ, Cheng CK, Fung RO, Wai W, Sin J, Seto WH, Yung R, Chu DW, Chiu BC, Lee PW, Chiu MC, Lee HC, Uyeki TM, Houck PM, Peiris JS and Leung GM: Facemasks and hand hygiene to prevent influenza transmission in households: A cluster randomized trial. Ann Intern Med 151(7): 437-446, 2009. PMID: 19652172. DOI: 10.7326/00034819-151-7-200910060-00142

21 Goossen GM, Kremer LC and van de Wetering MD: Influenza vaccination in children being treated with chemotherapy for cancer. Cochrane Database Syst Rev 8: CD006484, 2013. PMID: 23904194. DOI: 10.1002/14651858.CD006484.pub3

22 Committee On Infectious D: Recommendations for prevention and control of influenza in children, 2017-2018. Pediatrics 140(4), 2017. PMID: 28870977. DOI: 10.1542/peds.2017-2550

Received December 27, 2019 Revised January 14, 2020 Accepted January 15, 2020 